\title{
Interspecific Aggression Between Reef Corals with Reference to Their Distribution
}

\author{
C. R. C. Sheppard \\ 7 Rough Lea, Hunwick, Co. Durham DL15 ORH, United Kingdom
}

\begin{abstract}
About 700 observations were made of interspecific aggression between coral species on reefs of Chagos, Indian Ocean. From information on which species killed, or were killed by, others a rough hierarchy of coral dominance was made in which the commonest 54 species were categorised as aggressive, intermediate or subordinate. The degree of aggression shown by a species bears little apparent relationship to its morphology or taxonomic position, and most sub-orders and families considered contained species having a wide range of aggressive behaviour Corals that were most aggressive include the freeliving fungiids, Galaxea clavus, Acropora palifera, A. hyacinthus and Goniopora spp.; the least aggressive were Porites sp. and Seriatopora hystrix. Interspecific aggression is tentatively related to coral zonation, and it is shown that the most aggressive species are those that often form clearly defined, nearly mono-specific zones. The possible contribution of aggression to coral zonation is discussed and compared with the situation in the Atlantic Ocean where aggressive corals are, by contrast, more minor components of the reef.
\end{abstract}

\section{INTRODUCTION}

Competition for space between scleractinian corals on a reef has been studied in relation to several factors. Displacement by shading, growth rate and corallum shape have been investigated, and the advantage is generally accepted to be in favour of rapidly growing ramose forms or to forms suited to particular environmental conditions such as severe weather (e. g. Connell, 1973). The study of competition expanded significantly with the work of Lang $(1971,1973)$ on active aggression between different species of corals. Although it had been noted much earlier (Gravier, 1910, 1911; Catala, 1964) that corals sometimes killed their neighbours and grew over them, the possible ecological significance of this activity was not investigated further until the publication by Lang (1973) of a coral aggression hierarchy for Atlantic species. It was shown that the response of one species to another was very consistent, and this behaviour was related in brief to coral distribution on the reef. The hierarchy was developed by a combination of laboratory studies, by transplantation experiments and general observation, and included almost all Atlantic hermatypes. The basis of the aggressive capability was shown to be extracoelenteric digestion by extended mesenteric filaments, a property of some corals that had already been described (Yonge, 1930; Goreau et al., 1971).
Similar work on Indo-Pacific communities is lacking, although brief observations, also by Lang (1973), suggest a similar importance of the phenomena and proposed degrees of aggression for a few species.

During a study in $1978 / 79$ of the reefs of Peros Banhos atoll, Chagos Archipelago, certain areas were observed which had an almost monospecific dominance of one scleractinian species. Investigation into this revealed that the coral concerned, Galaxea clavus, was highly aggressive and killed tissue of almost every species with which it came into contact. Developing from this, an attempt was then made to determine a hierarchy for the commonest Chagos species to try and explain several features of coral distribution. This paper describes the approximate relative positions in the aggressive hierarchy of the most common corals on the atoll, relating it where possible to their distribution.

\section{METHODS}

The number of species pairs that could theoretically be investigated is the square of the number of species over two, which on Chagos, with over sixty genera, will be several thousand pairs. It was therefore decided to restrict observations to naturally occurring interacting pairs and not to artificially induced interactions by means of transplantation. Thus the natural interac- 
tions recorded represent the actual situation on the reef, and although the number so recorded was far fewer than the possible maximum, it did involve the fifty or so commonest species.

About thirty searches were performed for coral colonies that abutted, touched, or were in close proximity to those of another species. These were carried out in the lagoon slope, the seaward slope and on lagoonal knolls in approximately equal proportions (Fig. 1). On the seaward and lagoon slopes searches were divided equally in three arbitrary zones: 1-10m deep, 10-20 m deep, and deeper than $20 \mathrm{~m}$. On the knolls whose

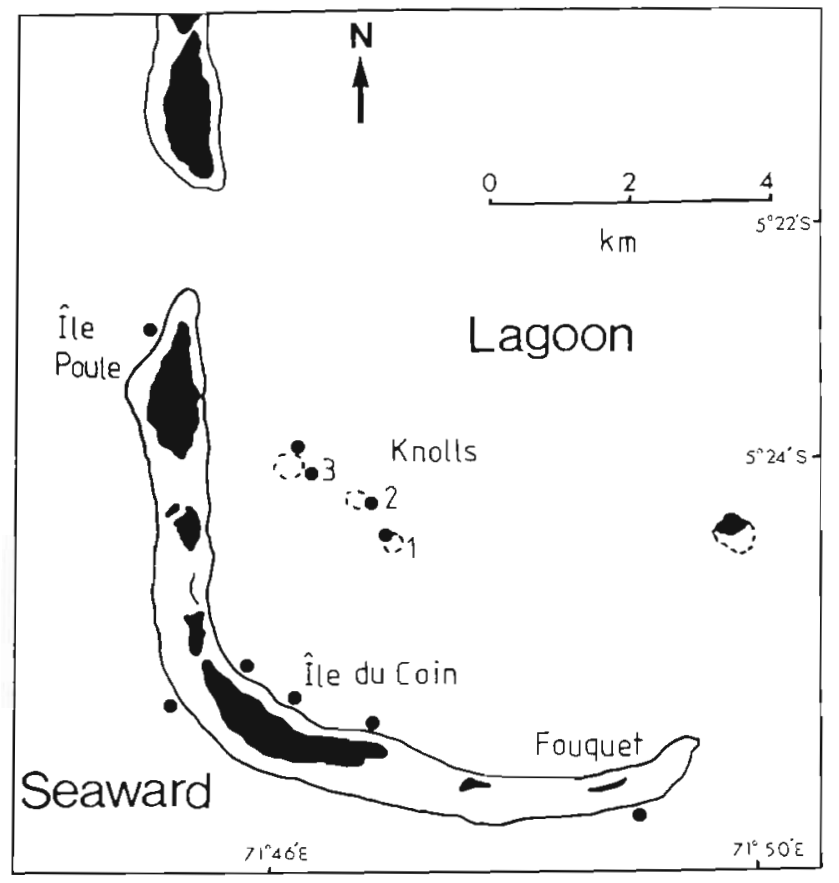

Fig. 1 Peros Banhos atoll, Chagos Archipelago (South West corner). Dots indicate observation areas

shallowest points were about $8 \mathrm{~m}$ deep, time was divided equally between 8-20 m and 20-30 $\mathrm{m}$ deep. Due to the extreme paucity of corals on the very shallow reef flats of Peros Banhos atoll (less than $0.5 \mathrm{~m}$ at low water) no interactions were found in this region.

On a typical search, limited only by air capacity or no-decompression time, between twenty and thirty examples of interacting coral pairs could be seen and identified. Occasionally in the 10-20 m zone on the lagoon reefs or knolls less were found, possibly because of overwhelming dominances of Acropora hyacinthus or $A$. reticulata. On the other hand the most consistently productive regions were the upper two zones of seaward reefs where 50 or more pairs could occasionally be found at one time. A total of 683 interacting pairs were recorded, involving 54 taxa. In most cases taxa were determined to species level. In others such as the free fungiids sub-genus was the limitation (though these were pooled for most purposes), and with Astreopora, Montipora and Goniopora the genus was the limit of classification in the majority of cases. With Acropora three species or species groups were separated and retained: A. palifera, A. humilis, and a group composed primarily of $A$. hyancinthus but which may have included the more tabular form A. reticulata or even others as well. Although the number of times that one species was found interacting with another during the survey is generally biased towards and dependent on the commonness of that species this was not always the case; for example $A$. hyacinthus/reticulata which formed huge tables on the knolls was seldom seen in contact with other species. The bias in the number of recorded conflicts does not, of course, bias the result observed of the interaction, and whenever a result seemed ambiguous or complicated by additional factors, such as when Acropora shaded as well as touched a neighbour, the observation was discarded.

\section{RESULTS}

The 683 interactions involved 260 different pairs of species. In 127 instances the interaction was observed only once and these are considered further in only a limited way. A total of 54 species were involved in all, and of these 24 were seen to interact with one to five other species only; these infrequently interacting species are also largely excluded from the results.

Table 1 presents (1) the list of species which were found interacting with at least six other species, and (2) the result of the interaction. The species in the left hand column kill the species indicated in the horizontal axis by a dot: a solid dot representing duplicated or multiply replicated results and an open dot an unduplicated observation. For example in the top row Pocillopora verrucosa was frequently seen killing Acropora humilis and once seen killing Astreopora sp. The column on the extreme right of the table shows the total number of species that the coral in the vertical axis kills, e. g. $P$. verrucosa was seen to kill ten other species. The row at the extreme bottom of the table represents the number of species that the coral in the horizontal axis is killed by, e. g. P. verrucosa is killed by two others. These numbers are often greater than the number of dots that they follow as they include records of kills of coral species not included in the table due to their infrequent interactions (with less than five other species).

\footnotetext{
- The full list of observations is available on request.
} 
Table 1. Interactions between the commonest reef corals. For explanation consult text

Pocillopora verrucosa (Ellis \& Solander) Stylophora pistillata (Esper)

Seriatopora hystrix (Dana)

Acropora palifera (Lam)

Acropora humilis (Dana)

Acropora hyacinthus (Dana)

Astreopora sp.

Montipora spp

Pavona clavus (Dana)

Pavona varians (Verrill)

Gardineroseris ponderosa (Scheer \& Pillai)

Fungia (all)

Halomitra philippinensis (Studer)

Goniopora spp.

Porites lutea (M. E. \& H)

Porites andrewsi (Vaughan)

Favia favus (Forskal)

Favia stelligera (Dana)

Goniastrea pectinata (Ehr)

Leptastrea transversa (Klunzinger)

Cyphastrea microphthalma (Lam)

Echinopora lamellosa (Esper)

Galaxea clavus (Dana)

Ctenella chagius (Matthai)

Lobophyllia corymbosa (Forskal)

Symphyllia radians (M. E. \& H)
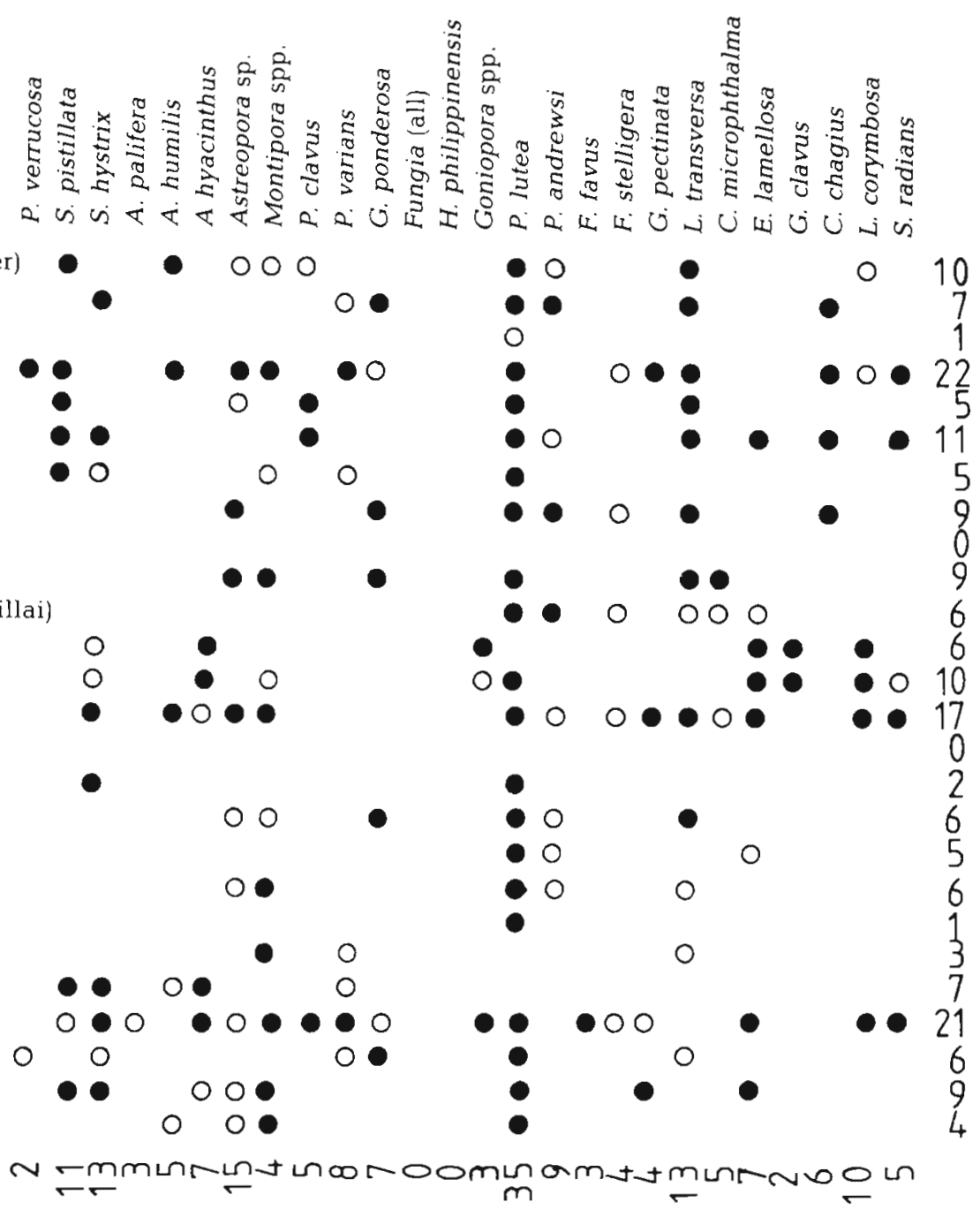

\section{Position of Families}

\section{Pocilloporidae}

The Pocilloporidae showed a wide spread of aggression amongst its commonest species. Pocillopora verrucosa was largely dominant in its conflicts, while Stylophora pistillata showed a more even number of victories and defeats. Seriatopora hystrix however was very subordinate and was damaged by almost every other species with which it came into contact.

\section{Acroporidae}

Species of Acropora showed a large number of interactions and in most were the aggressors. A. palifera particularly damaged almost all species it encountered and $A$. hyacinthus similarly dominated most other species. A. humilis, however, was subordinate to almost as many as it dominated. Astreopora spp. and Montipora spp. were conspicuously different from their cofamilial relations, each being killed by many more species than they killed. In the case of Montipora it was observed also that on twelve occasions different species of the genus touched, and on all occasions both colonies abutted without an aggression response.

\section{Agariciidae}

These showed only mild or no aggression in the three representative species of the family. Two, Pavona varians and Gardineroseris ponderosa, each killed or 
were killed by similar numbers, while $P$. clavus, a very massive form, appeared very subordinate and failed to kill any other species with which it was in contact.

\section{Fungiidae}

This group was very aggressive indeed when contact was made with attached corals. However the freeliving nature of most of its members complicated the observation. Despite the large number present, of four sub-genera of Fungia on the lagoon slopes (Danafungia, Fungia, Pleuractis, Verrillofungia) very rarely was one found in contact with attached corals. When one was found, Fungia was invariably the aggressor, but generally the distance between a Fungia and another coral was slightly too great to expect a reaction. The mobility of this genus must be suspected as being a contributing factor in this effect, and may possibly be used to avoid conflict. Halomitra philippinensis, while unattached, is not mobile in the same way and was found in contact with considerably more species, all of which it damaged. Herpolitha limax also, while excluded from the table, did kill two other species (Porites lutea and Montipora sp.) and was killed by none. These corals were the only ones which were never seen to be killed by another coral. Interestingly, however, their distribution was often clumped, with the Fungia sub-genera, Halomitra, Herpolitha and Herpetoglossa all touching. In all such cases there was never any observed conflict between members of this family. Further observations in aquaria designed to elucidate relative aggression amongst the free corals also failed to show any aggression response.

\section{Poritidae}

This family contained genera at both extremes of the aggression hierarchy. Goniopora spp. (mostly G. stokesi) were aggressive, killing polyp tissue of most species that were situated close enough to it. The exceptions were the fungiids and Galaxea clavus. Fur. ther, the killed areas were the greatest of any of the interactions noted. Of significance here may be their very long polyps, sometimes extending to $10 \mathrm{~cm}$ in daytime, and little if anything seemed to survive within their sweep. Conversely Porites held the position of the most subordinate genus of all. P. Iutea was common on the shallow reef, and in numerous contacts with 35 species it was universally subordinate. The branching species $P$. andrewsi was nearly as subordinate, killing only $P$. lutea and Seriatopora hystrix. The latter, as noted earlier, is particularly subordinate: it is killed by all the corals listed except $P$. Iutea.

\section{Faviidae}

These showed a wide spread of aggressive behaviour. Cyphastrea microphthalma, Favia stelligera, Goniastrea pectinata and Echinopora lamellosa all killed or were killed by similar numbers of species in these observations. Favia favus, however, appeared to dominate double the number of species that it was subordinate to. Conversely Leptastrea transversa was amongst the most subordinate of all, being killed by thirteen others. It ranks with Porites lutea, which was the only species that it was seen to kill, $P$. andrewsi and Seriatopora hystrix at the bottom of the hierarchy.

\section{Oculinidae}

The only species of this family represented is Galaxea clavus. It is extremely aggressive and the most dominant of the attached corals, killing even Goniopora spp. and Acropora palifera. It was killed only by the Fungiidae and it damaged twenty others (Fig. 2).

\section{Meandrinidae}

Of interest because of its very limited geographical distribution is Ctenella chagius, the only Indo-Pacific member of this family. This species was seen reacting with twelve others and showed an even number of victories and defeats. It killed those shown above to be very subordinate, and was killed by the common aggressors, including Acropora palifera and A. hyacinthus though it was sometimes variable in its response and prevented some tabular species of Acropora from overgrowing it.

\section{Mussidae}

Lobophyllia corymbosa andSymphyllia radians showed a more or less intermediate position in the aggression hierarchy, each killing about as many species as it was killed by. This is in marked contrast to the position of this family in the Caribbean where it was shown to contain the most aggressive corals (Lang, 1973). Furthermore, on ten occasions these two genera were seen to be in close physical contact with each other on the reef and on all occasions no interaction had occurred or was taking place. The tissues of each that touched those of the other appeared normal in every way (Fig. 3).

It is not possible to construct an exact hierarchy in the way achieved by Lang (1973) for Atlantic species since not every coral tabulated was observed in contact with every other one. Instead, however, a categorised 


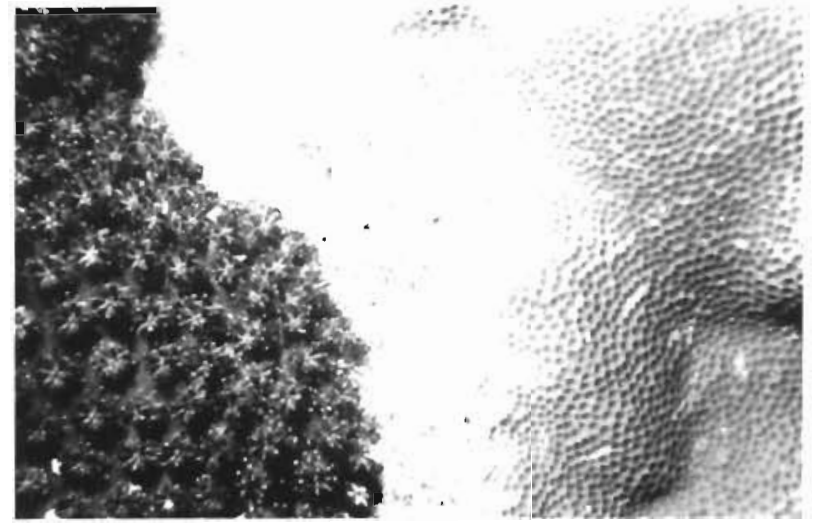

Fig. 2. The most aggressive attached coral Galaxea clanus (left) killing the most subordinate coral Porites lutea in typical fashion

hierarchy may be drawn up for several of the species (Table 2). It was felt that three categories could be safely made at least; a species which was dominant in more than two thirds of its observed interactions is listed under the first "aggressive" column, while those that were dominant in less than one third are termed "subordinate", the remainder being "intermediate". It is possible however that the category of some species could change if much more searching revealed interactions of a different nature to those recorded here for the species.

The degree of aggression within a family can vary considerably therefore and only a few families showed much consistency within their species. Also at the level of sub-order generalisation seems to be impossible as the most aggressive corals belong to all three of the sub-orders represented in this study. The other two sub-orders, the Caryohylliina and Dendrophylliina are not represented at all here due to their relative scarcity on the Chagos reefs. This contrasts with the position of the Faviina as the most dominant Atlantic corals (Lang, 1973). At generic level rather more consistency is noticed, as may be expected, although here too some spread is evident.

Amongst the aggressive species there is no common morphological factor. Acropora palifera is ramose in form when it occurs in the lagoonal reefs, but has no lobes or branches on the shallow seaward reefs. $A$. hyacinthus is highly ramose and Goniopora spp. and Favia favus are massive. The free fungiids and the encrusting to foliose Galaxea clarus complete the spectrum of coral types and sizes to be found in the aggressive category. Amongst the subordinate group there is only a little more correlation with corallum shape. Porites, Pavona, Astreopora and Leptastrea are all massive. However Porites andrewsi and Seriatopora hystrix are ramose and Montipora spp. are all encrusting.

Thus it is clear that amongst these corals the degree of aggression or subordination bears no apparent relationship to taxonomic position or corallum shape. Size of polyp likewise has no obvious bearing on these categories, although it may well have an effect in some individual cases, discussed later.

\section{Aggression and Coral Zonation}

The reef zonations of Peros Banhos are in several cases typical of many Indo-Pacific atolls and in others

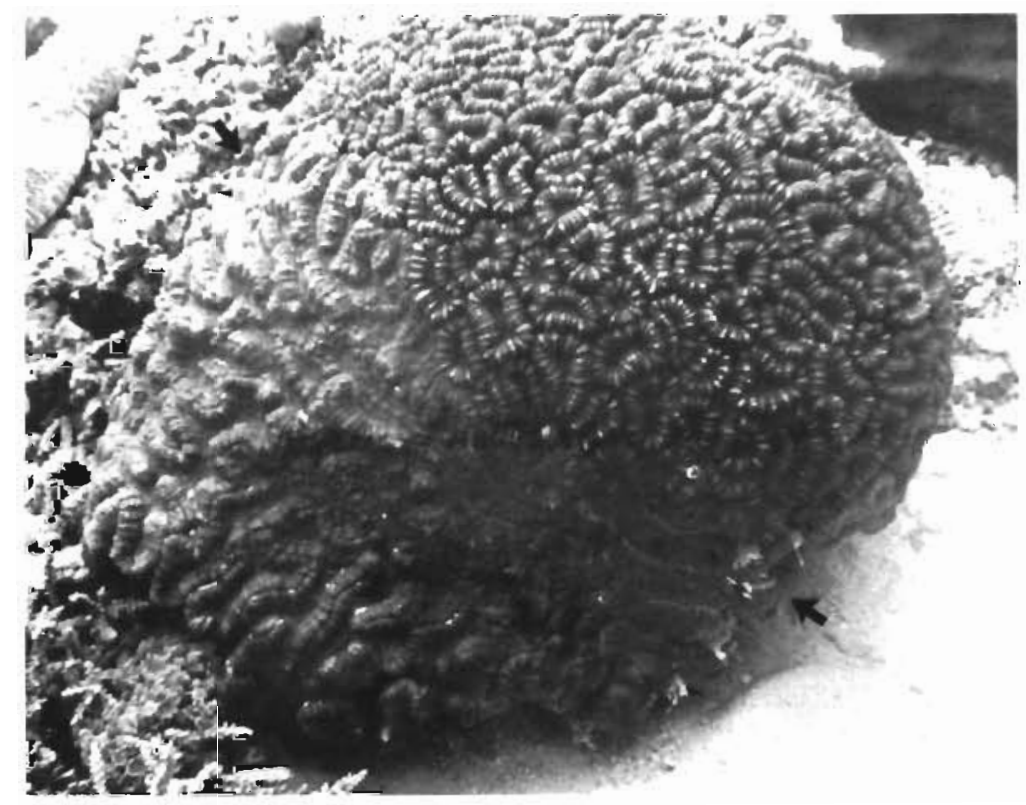

Fig. 3. Symphyllia sp. (lower left) touching Lobophyllia corymbosa (upper right). No interspecific aggression response can be seen along the line of contact (ends of line of contact arrowed) 
apparently exceptional. Briefly, on the lagoon side, beyond the edge of the reef flat a zone of conspicuous Porites boulders dominated to about $6 \mathrm{~m}$ deep, followed by a zone of very dense Acropora hyacinthus to 15 m. Following this, a zone entirely dominated by Galaxea clavus existed to the lagoon floor at $25 \mathrm{~m}$. On the seaward slope, a zone of encrusting Acropora palifera occurred to $5 \mathrm{~m}$, followed by a region of high and increasing diversity to $20 \mathrm{~m}$ with no conspicuous zonation. Beyond this, diversity declined constantly until a region of Pachyseris from $25 \mathrm{~m}$.

Within particular zones of the reef some hierarchies can be defined more exactly, and in some cases the order of aggression correlates well with the coral distribution in the zone. In the zone $20-30 \mathrm{~m}$ on the lagoon slopes of Peros Banhos the diversity is considerably reduced from the peak just above $20 \mathrm{~m}$. Here three species dominated in the order Galaxea clavus most abundant, Lobophyllia corymbosa, and Echinopora lamellosa least abundant. Numerous mounds were also found which rose from the lagoon floor at 30 $m$ to heights of 4 or $5 \mathrm{~m}$ above the floor, isolated from the reef slope by large areas of sand. These mounds were over $95 \%$ G. clavus; some of $30 \mathrm{~m}$ across and $3 \mathrm{~m}$ high contained, as far as could be seen, no other coral species at all. The form of the coral was largely foliaceous with each leaf growing above older, dead leaves, such that blocks up to fifteen layers thick could be discerned. Most of these areas however had several colonies of $L$. corymbosa and E. lamellosa as well. Of these corals $G$. clavus killed both the others, and $L$. corymbosa killed E. lamellosa, so that in this association the hierarchy $G$. clavus - L. corymbosa - E. lamellosa existed, which exactly reflected the densities of each species. Other species that existed on these areas were primarily the free fungiids, with lesser numbers of Euphyllia glabrescens, E. turgida and Goniopora spp., especially $G$. stokesi, around the periphery but within the mounds as well.

In this, one of the simplest associations, the aggression of each species correlated simply, if too simplistically, with abundance. In shallower regions on the lagoon slope Acropora hyacinthus dominated and on the seaward slope. A. palifera also showed a domi-

Table 2. Coral species occupying the three categories of relative aggression: aggressive, intermediate and subordinate

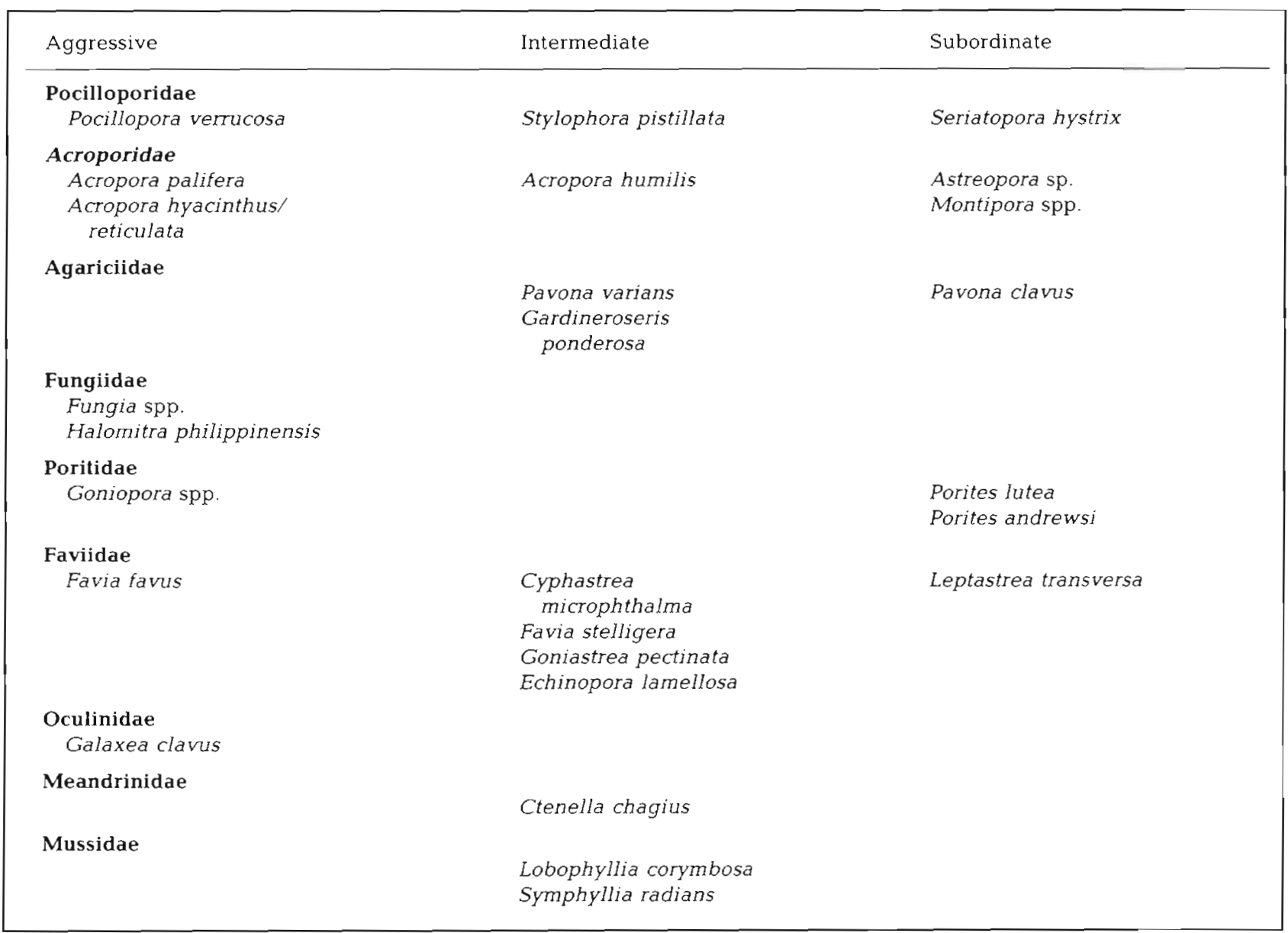


nance to $5 \mathrm{~m}$. In both cases these corals were very aggressive. Lang (1973) points out that aggression will help a coral to survive even if it grows slowly and that this capability evens out the advantage that rapid growth gives to competitors. These Acropora species, however, appear to have both advantages and hence may be expected to hold a strong position. This of course they seem to do within their own particular ranges of environmental conditions and depths. It is of interest that they are subordinate only to Galaxea clavus, Lobophyllia corymbosa and Echinopora lamellosa, apart from the fungiids, which hold similar dominance levels or exist in great abundance deeper down.

In the shallowest water of the lagoon slope Porites boulders were particularly abundant. This region, from 2-4 $\mathrm{m}$ deep, was one of the few where Acropora was not dominant, although $A$. humilis was conspicuous. However, the position of Porites in the hierarchy was bottom, and it was killed by every one of the 36 species that it touched. But although Porites is very subordinate it does succeed extremely well and is very important in this part of the reef. It has indeed an importance on the reef as a whole that is second only to Acropora and is apparently a very rapid grower in terms of mass increase (Wells, 1956).

Probably, to be subordinate is of little consequence once the colony has reached a moderate size; it is in the young stages that aggression is most significant. A young subordinate form settling near an aggressor may well be eliminated, while a young aggressive form settling near an established subordinate form may grow unhindered. It would, therefore, be beneficial to a subordinate coral to be able to withstand assault and to tolerate and contain dead areas. This Porites appears well able to do. Larger colonies more commonly than not have numerous dead patches on them, even serving as substrate for numerous other species. Its settlement and early growth, however, are clearly adequate to give rise to enormous coral growth. Its success in Chagos is mostly in that region which is very affected by weather, a variable that its massive form is best able to resist, and this may help to provide the compensation for its total lack of aggression. However, the position of Porites may not always be comparable between reefs; in the Seychelles, for example, it characterises more sheltered areas (Rosen, 1971).

\section{Region of Interaction}

Usually the observation which of the pair is subordinate and which is dominant was straightforward. With encrusting species there is generally a strip up to $0.5 \mathrm{~cm}$ wide between them which may be bare or may be colonised by filamentous algae and occasionally other sessile fauna. Various degrees of such colonisation between the same pairs indicate that this is merely the result of the passage of time. When colonised, the strip sometimes had to be cleared before determining the nature of the interaction.

Most commonly, the subordinate species is distinguished by an area of dead, bleached corallites bordering the line of contact while the dominant species shows living and actively dividing corallites up to its edge. Frequently, the dominant coral may overgrow the subordinate one as well.

Amongst branching corals the position was often more marked. Whole branches of Stylophora pistillata were seen killed by an intercepting branch of Acropora hyacinthus, and a branch of the latter could penetrate

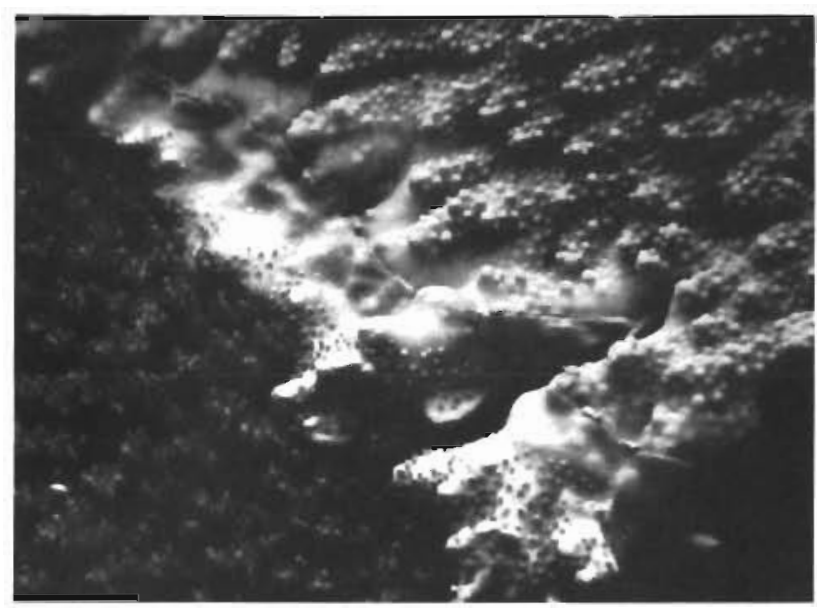

Fig. 4. Two species of Acropora meeting. Neither kills the other but fusing takes place resulting in an area of high calcification with sparse corallites

deeply into colonies of Seriatopora hystrix or Porites andrewsi, marking its passage by extensive dead areas of the subordinate corals. Dead areas may be bleached or have colonising biota on them, and often in the case of Acropora spp. the conflicting portion of the coral would show heavy calcification, sometimes a deflection away, and often a more sparse covering of corallites as well (Fig. 4)

Similar effects were seen between a ramose and a massive form, and between two massive forms. Where a ramose form came into contact with Porites, for example, the interaction was marked by a dead circle around the latter of about $2 \mathrm{~cm}$ diameter, perpendicular to which would be the encroaching ramose tip. Occasionally a tip of Acropora would be cemented onto the subordinate corallum and show heavy calcification with sparse corallites. When both partners were massive such overgrowing was rarely seen and growth seemed to stop just short of actual contact.

Where the corallites of a subordinate species are 
large, such as with Lobophyllia, it was commonly observed that half a polyp only might be affected. A Lobophyllia abutting a Galaxea or Goniopora, for example, would show a killed zone $1-2 \mathrm{~cm}$ from the latter, and this would be of fairly uniform width such that parts of a calice falling closer than this would be bare and white, while the more distant part - falling presumably outside the zone of the aggressor's influence - would contain apparently healthy polyp tissue.

The size range of the dead gap between a pair of corals fell broadly into two groups: up to $0.5 \mathrm{~cm}$ for small polyped, encrusting species, and up to $2 \mathrm{~cm}$ or more in the case of most others regardless of polyp size. Within any pair, the exact gap may vary considerably within this approximate range; observations suggest that microhabitat, especially that controlling water movement, may be responsible.

Lang $(1971,1973)$ has clearly demonstrated the vital part that extracoelenteric feeding has in interspecific aggression and has shown that gaps of several centimetres can be crossed by the filaments concerned. Such a response is doubtless stimulated by chemoreception on the part of the aggressor (Muscatine, 1973), so that chemoreceptive properties together with the ability to extrude filaments may be the basis of such aggression. However, this aspect of aggression does not seem to account entirely for the observed interactions in many cases where the distance between the corals was several centimetres or more. Whereas such a gap may readily be crossed by filaments from a large polyp, such as a mussid, it is over ten times the diameter of many of the smaller polyps that nevertheless seem to cast their effect over this distance. It is a common observation, discussed also by Connell (1973), that tables of Acropora, for example, grow around some massive forms, leaving a gap several centimetres wide into which the subordinate coral may not grow

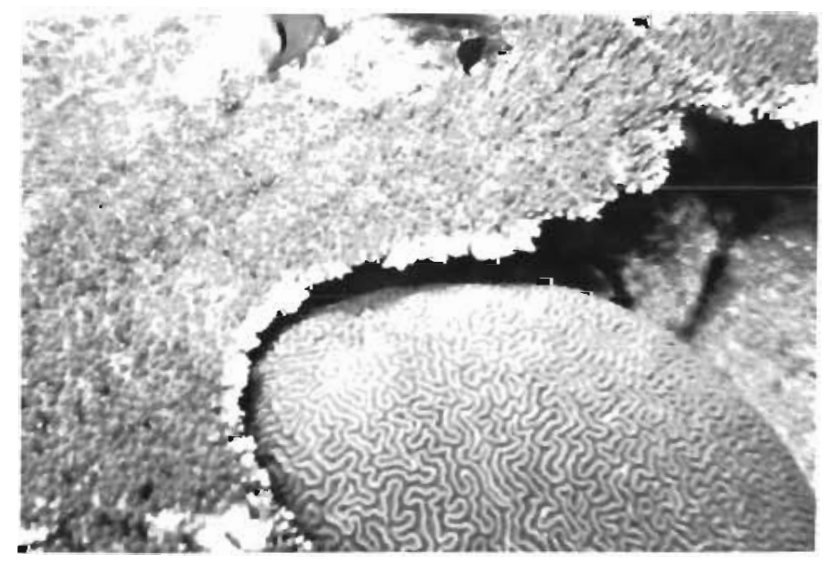

Fig. 5. Ctenella chagius (right) prevents a tabular Acropora colony (left) from approaching closer than $3-5 \mathrm{~cm}$. The polyps of $C$. chagius are $0.3 \mathrm{~cm}$ across with tentacles attaining a maximum length of $0.4 \mathrm{~cm}$

(Fig. 5). It is difficult to imagine mesenteric filaments from such an aggressor successfully crossing such a gap to prevent growth into it, and it may be that an associated mechanism, perhaps connected with toxin secretion is involved. Immunological responses resulting in death of subordinate corals have already been demonstrated (Hildemann et al. 1977).

\section{Coral Pairs Producing No Interactions}

Table 3 presents species pairs which were observed in contact but which produced no response from either coral. All were observed in situ, except for the pairs of free-living fungiids where artificially enforced contacts in tanks were used as well. The broad range of pairs involved is considerable and shows that not only may there be no reaction between different species of one genus but that different genera and even families and sub-orders may not respond in this way. Further, comparison with Table 1 will show that one or two pairs appear in both tables indicating that in these cases only sometimes will these pairs show an interaction of this nature. Lang (1971) used the existence of a response to distinguish between species of Scolymia and Potts (1978) similarly investigated this method in

Table 3. Pairs of coral species that showed no dominance interaction at points of contact

Acropora palifera

Lobophyllia corymbosa

Lobophyllia corymbosa

Lobophyllia corymbosa

Lobophyllia corymbosa

Lobophyllia corymbosa

Lobophyllia corymbosa

Lobophyllia corymbosa

Symphyllia radians

Goniopora sp.

Goniopora sp

Goniopora sp

Porites lutea

Porites lutea

Porites andrewsi

Porites andrewsi

Gardineroseris ponderosa

Gardineroseris ponderosa

Gardineroseris ponderosa

Montipora spp.

Favites halicora

Echinopora lamellosa

Halomitra philippinensis

Halomitra philippinensis

Halomitra philippinensis

Herpolitha limax

Fungia (Verrillofungia)

Fungia (Verrillofungia)

Fungia (Verrillofungia)

Fungia (Fungia)
Pocillopora verrucosa

Halomitra philippinensis

Seriatopora hystrix

Echinophyllia sp.

Symphyllia radians

Pavona clavus

Fungia (Danafungia)

Fungia (Fungia)

Pocillopora verrucosa

Porites sp.

Montipora sp.

Fungia (Danafungia)

Porites sp.

Leptastrea transversa

Seriatopora hystrix

Pavona clavus

Porites sp.

Pavona clavus

Pavona varians

Montipora spp.

Favites abdita

Seriatopora hystrix

Herpolitha limax

Fungia (Fungia)

Fungia (Danafungia)

Fungia (Danafungia)

Funiga (Pleuractis)

Fungia (Fungia)

Fungia (Danafungia)

Fungia (Pleuractis) 
Acropora species. It should be clear however that the lack of a response does not necessarily indicate a similarity of species, a point which is usually obvious but which may lead to complications within a genus. Conversely, future work may show that the existence of a response may not indicate a species difference, and at present the amount of genotypic variation or difference needed to induce this response is not at all clear.

\section{Interactions of Alcyonaria, other Octocorals and Mil-} lepora with Scleractinian Corals

The Alcyonaria form a conspicuous part of most Chagos reefs where they nearly equal the scleractinian corals in terms of cover between 3 and $25 \mathrm{~m}$; their responses when in contact with scleractinian corals were observed. When one of each touched, the most frequent result was that neither appeared to cause any damage to the other outside the actual area of contact where abrasion, light loss and other factors caused changes. Almost as commonly, a soft coral would simply overgrow a stony coral. In these cases the overgrown part would clearly have been killed by the act of overgrowth but unlike the corresponding wholly scleractinian situation there would be no visible killed band, however narrow, ahead of the advancing alcyonarian, and the death of the stony coral may be entirely attributed to the overgrowth process and not at all to any feeding or other response. The stony coral appeared in all cases where overgrowth occurred to be to 'subordinate' (Fig. 6). The mesenteric feeding response of scleractinian corals was never observed to have been induced by an Alcyonaria or indeed by the stony octocorals Heliopora and Tubipora, or by Millepora. Conversely the Alcyonaria together with the stony

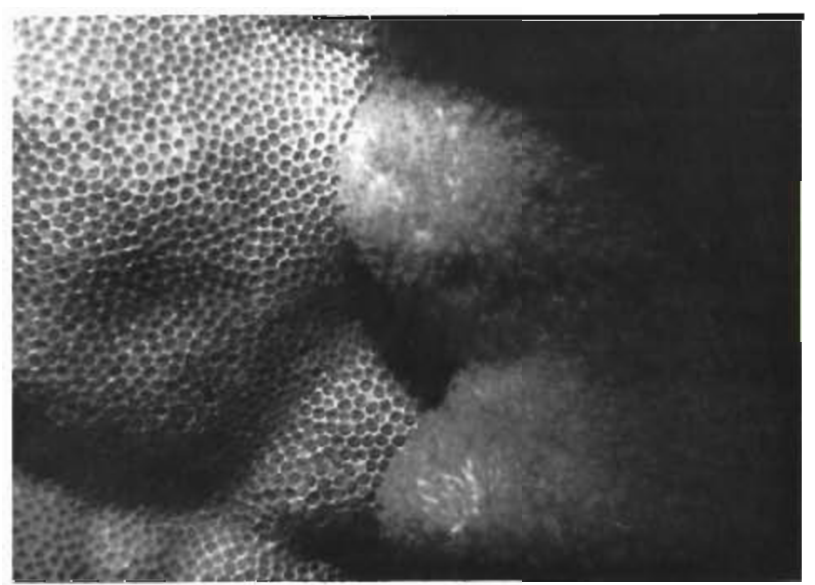

Fig. 6. The coral genus Porites (left) is the most subordinate genus; however, not even these are attacked by soft corals but are merely overgrown

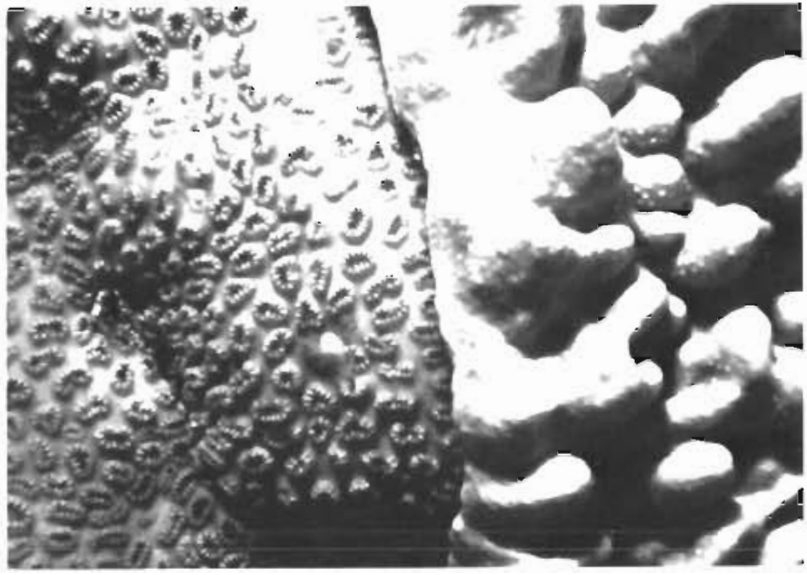

Fig. 7. Two touching species of 'soft coral'. No digestive interaction occurred between any observed pair of soft corals

octocorals did not appear to be capable of forming aggressive responses of the type observed for stony corals, either amongst themselves or with stony corals (Fig. 7). Millepora sometimes differed slightly however, in that a narrow band of dead coral of up to $2 \mathrm{~mm}$ wide preceded its advancing edge. The small width of this band would be in accordance with the small Millepora zooid but made detailed observation difficult. With this organism especially it is perhaps possible that the action of nematocysts against the coral polyps played an important role in causing the killed band that preceded its advance (Fig. 8)

The implication from these negative reactions is that the scleractinian corals cannot digest soft corals extracoelenterically, even in the case of species that are very capable of this mode of feeding amongst themselves; it is possible that no chemicals are exuded from soft corals that are recognised as food by the stony corals. Therefore, the emphasis in this type of feeding must be as much on recognition by chemoreceptors as on ability to extrude filaments.

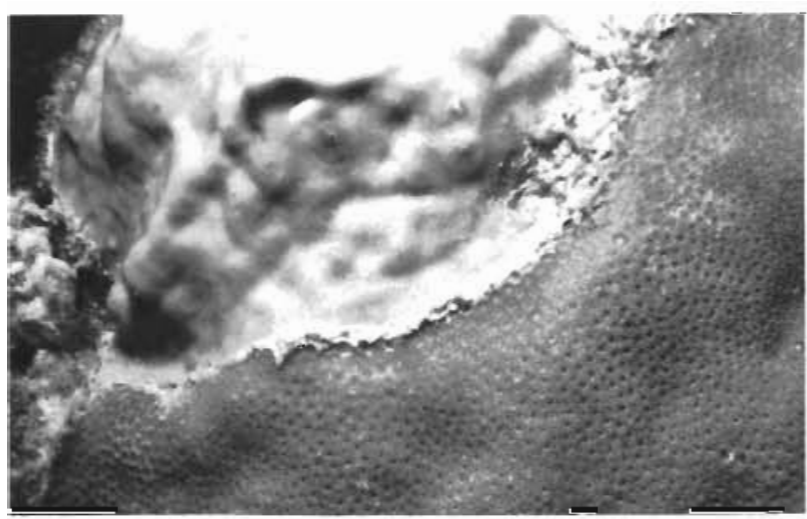

Fig. 8. Porites sp. is overgrown by Millepora sp., but only a very narrow strip ahead of Millepora is killed 


\section{DISCUSSION}

In the Atlantic Ocean the highly aggressive corals belong to the Mussidae and Meandrinidae, both members of the Faviina (Lang, 1973). The Faviidae and Acropora spp. were shown to be moderately aggressive, and Porites ranked, amongst others, with the least aggressive corals on Jamaican reefs. Some similarities of aggression between the Atlantic and Indo-Pacific coral faunas are evident therefore. The most notable is Porites which is least aggressive on the reefs of Peros Banhos. In the case of Acropora the term 'moderately aggressive' understates the position of the genus on Chagos, since two of its most common species, $A$. palifera and $A$. hyacinthus showed evidence of killing many more species than they were killed by. A. humilis, however, does fit a moderately aggressive category. The faviids on Chagos similarly correspond in general to an intermediate category although they have representatives at both ends of the hierarchy. In all instances of course the species themselves differ from those in the Atlantic Ocean.

Amongst the highly aggressive species the situation differs considerably. The most aggressive genera on Chagos are, with the exception of Acropora and Favia, genera that do not exist in the Atlantic Ocean. Pocillopora verrucosa was found to kill ten species and was killed by only two. The free-living fungiids, Goniopora and Galaxea all showed similar or higher ratios of success. In the Caribbean the mussids occupied the top positions but in Chagos the common mussid corals Lobophyllia and Symphyllia were constantly killed by the aggressive group. Thus they are displaced into an intermediate category. The complete lack of any interaction between the most common species of these two genera, as illustrated in Figure 3, illustrates further the lack of aggression by these in the Indo-Pacific Ocean.

There is thus one important difference between the Caribbean and Chagos reefs in this respect. Lang (1973) demonstrates that in the former province the highly aggressive corals are to be found in all reef habitats but constitute relatively minor components of the reef. In Chagos, by contrast, many of the most aggressive are extremely dominant in certain zones. The species of Acropora considered and of Galaxea are all, as discussed, very markedly dominant in certain zones. Pocillopora verrucosa likewise is a common species, in shallow waters at least. The others are minor components throughout.

If aggression does indeed have a marked bearing on coral distribution its contribution to the total order of ecological coexistence might seem to be very clear for several species, though the other ecological forces that act on corals are stronger in their effects. Why otherwise would Acropora hyacinthus dominate only to 10 $\mathrm{m}$ and Galaxea clavus assume the same role deeper down, and how otherwise could the subordinate Porites be so prominent in the shallow regions? The exact contribution of coral aggression is therefore difficult to assess quantitatively, and its relative importance compared with environmental factors such as light attenuation, exposure, and with output of larvae and other factors is still not very clear. However, as pointed out by Lang (1973), the advantage of aggression at the individual level could determine whether or not the coral survives and amongst forms such as $G$. clavus this ability can at the very least help to obtain and then to maintain dominance.

The competition for space between corals on a reef is generally understood to be intense. The zonations found on any one reef with respect to depth, light and exposure are the visible result of environmental forces, and at any one time - except in instances of storm damage or man-induced changes which displace the equilibrium - the competion has spatially resolved itself. Of numerous published reef descriptions many show similar zones indicating that the resolution produces similar patterns in different areas. However, many show differences even in apparently similar areas indicating that other, often unconsidered, factors are operating and an aggression hierarchy should perhaps be one factor to be taken account of in any ecological study or reef model.

Acknowledgements. This work was carried out on the Joint Services Chagos Research Expedition. The numerous sources of financial support are gratefully listed in the Report of the Expedition.

\section{LITERATURE CITED}

Catala, R. L. A. (1964). Carnival Sous La Mer, Sicard, Paris.

Connell, J. H. (1973). Population ecology of reef building corals. In O. A. Jones and R. Endean (Eds), Biology and Geology of Coral Reefs, Vol. II, Biol. I. Academic Press, London. pp. 205-246.

Goreau, T F., Goreau, N. I. and Yonge, C. M. (1971). Reef corals: Autotrophs or heterotrophs? Biol. Bull. mar. biol. Lab., Woods Hole, 141, 247-260.

Gravier, M. C. (1910). Sur la lutte pour I'existence chez les Madréporaires des récifs coralliens $C . r$ hebd. Séanc Acad. Sci., Paris, 151, 955-956.

Gravier, M. C. (1911). Les récifs et les madréporaires de la Baie de Tadjourah. Annls Inst. océanogr., Monaco, 2, 1-104.

Hildemann, w H., Raison, R. L., Hull, C. J., Akaka, L. Okumoto, J and Cheung, G. (1977). Tissue transplantation immunity in corals. Proc. 3rd Int. Coral Reef Symp., $1977,537-543$.

Lang, J. (1971). Interspecific aggression by scleractian corals 1 The rediscovery of Scolymia cubensis Milne Edwards \& Haime. Bull. mar. Sci, 21, 952-959.

Lang, J. (1973). Interspecific aggression by scleractinian 
corals. 2. Why the race is not only to the swift. Bull. mar. Sci. 23, 260-279.

Muscatine, L. (1973). Nutrition of corals. In O. A. Jones and R. Endean (Eds), Biology and Geology of Coral Reefs, Vol. II. Biol. I. Academic Press, London. pp. 77-115.

Potts, D. C. (1978). Differentiation in coral populations. Atoll Res. Bull., 220, 55-74.

Rosen, B. R. (1971). Principal features of coral ecology in shallow water environments of Mahe, Seychelles. Symp. zool. Soc. Lond., 28, 163-183.

Wells, J. (1956). Scleractinia. In R. C. Moore (Ed.), Treatise on Invertebrate Paleontology. Univ. Kansas Press and Geol. Soc. Am. pp. F328-F444.

Yonge, C. M. (1930). Studies on the physiology of corals. 1 Feeding mechanisms and food. Scient. Rep. Gt Barrier Reef Exped., 1, 14-57

This paper was presented by Dr. D. Kühlmann; it was accepted for printing on September 6, 1979. 